\title{
An Epidemiologic Study on Type 2 Diabetic Foot Disorders in Indonesia -A Perspective from an Uncontrolled Blood Glucose Level until Amputation- Julcrithno Irawan*a, Mulawardi Mulawardi
}

Introduction: The prevalence of diabetes mellitus is continuously increasing worldwide and expected to reach more than 500 million people in 10 to 15 years later. In Indonesia, neglected case for diabetic foot and uncontrolled blood glucose level make the amputation rate is higher. The aim of this study is to describe the diabetic foot disease among Indonesian population, underlying disease, and the all of the treatments in our hospital.

Method: All conservative and operative procedures in diabetic foot during the period of January 2017 - December 2018 was collected in Wahidin Sudirohusodo Hospital. All demographic data, disease classifications, laboratory results, and treatments were collected from medical records retrospectively.

Results: In total of 229 patients, were found 1.02:1 male-to-female ratio of patients, where most of patients were in the sixth decade as much as $41 \%$. The most Wagner classification was in the Grade 4 (29.\%), HbA1C $>6.5 \mathrm{mg} / \mathrm{dL}$ was found in $68.6 \%$ patients with higher WBC counts in $71.2 \%$. Of $44.1 \%$ patients were treated conservatively, whilst 127 (55.9\%) patients were treated operatively, which were debridement and amputation procedures. We found mortality rate of $3.9 \%$ as an outcome.

Conclusion: The incidence of diabetic foot is increasing. Uncontrolled blood glucose levels ( $\mathrm{HbA} 1 \mathrm{C})$ become one of the causes. Proper handling on controlling blood glucose and podiatry treatment can decrease morbidity and mortality rates.

Keywords: diabetic foot, Wagner, amputation, Indonesia https://doi.org/10.36864/jinasvs.2020.2.010
Copyright (C) 2020, The Indonesian Society for Vascular and Endovascular Surgery

JINASVS 2020;1(2):41-45

Correspondence: julcrithno@gmail.com

aM.D., Department of Surgery, Dr. Wahidin Sudirohusodo, South Sulawesi, Indonesia

\section{INTRODUCTION}

Diabetic foot is currently a major health issue worldwide, due to increasing cases, ulcers which are chronic and difficult to heal, experiencing infections, and limbs ischemia with the risk of amputation even a life-threatening. ${ }^{1}$ Diabetes is a major cause of pathology in the legs, causing ulceration of the feet due to neuropathy, infections, and ischemia. Diabetic foot occupies second position for amputation on nontraumatic cases in the United States and Canada. ${ }^{2}$

The prevalence of type 2 diabetes mellitus (DM) will be continuously increasing worldwide and expected to reach more than 500 million people in 10 to 15 years later. ${ }^{3}$ WHO (World Health Organization) predicts the increasing numbers of type $2 \mathrm{DM}$ in Indonesia from 8.4 million in the year 2000 to 21.3 million in 2030. As DM's prevalence rate increases, the DM's chronic complications will also increase. ${ }^{4}$

Cipto Mangunkusumo Hospital in Indonesia reported numbers of death and amputation are $16 \%$ and $25 \%$ in $2003 . .^{5}$ In the USA, diabetic foot ulcers spent billions of dollars during patient care in the hospital and the consequences of the defects it causes. Diabetic foot complications is one of the greatest causes of morbidity in patients with DM. ${ }^{2}$
Based on it, we were planning to conduct a study of patients characteristics and treatments in the diabetic foot cases during the January 2017 December 2018 period at Wahidin Sudirohusodo Hospital.

\section{METHOD}

The purpose of this study was to determine the characteristics of patients who diagnosed with diabetic foot, concerning also the treatments that have been done. This was a descriptive retrospective study. Data on this research was derived from the medical record of the patient at Wahidin Sudirohusodo Hospital. The population of this study was patients who comes to get a treatment at Wahidin Sudirohusodo Hospital who were handled by vascular surgery division and other related sections such as internal medicine within 2 years (January 2017 December 2018).

From the obtained data, we recorded gender, age, Wagner classification, HbA1C level, leucocytes/WBC count, osteomyelitis condition, treatment, amputation level, comorbidities disease, and outcome. All the collected data was processed, analyzed, and presented by table and narrative and compared to the results of various literature. 


\section{RESULTS}

From the results of retrospective data in study population, we found 229 patients from January 2017 to December 2018 at Wahidin Sudirohusodo Hospital. Male and female distribution were almost in same proportion ( 50.1 vs. $49.9 \%$ ) with the mostly in fifth and sixth decade of life (>75\%). More than $68 \%$ cases were in Wagner III and higher, with level of $\mathrm{HbA} 1 \mathrm{C}$ also $>6.5 \mathrm{mg} / \mathrm{dL}$. Mostly cases (>55\%) were treated operatively (debridement and amputation), see Table 1.

Table 1. Characteristic of the Patients

\begin{tabular}{lr}
\hline Variable & Total n (\%) \\
\hline Gender & \\
Male & $116(50.1)$ \\
Female & $113(49.9)$ \\
Age, years & $2(0.8)$ \\
$<30$ & $7(3.2)$ \\
$30-40$ & $41(17.9)$ \\
$40-50$ & $85(37.1)$ \\
$50-60$ & $94(41.0)$ \\
$>60$ & \\
WAGNER CLASSIFICATION & $4(1.7)$ \\
WAGNER I & $54(23.6)$ \\
WAGNER II & $58(25.3)$ \\
WAGNER III & $68(29.7)$ \\
WAGNER IV & $45(19.7)$ \\
WAGNER V & \\
HbA1C & $72(31.8)$ \\
<6.5 mg/dL & $157(68.2)$ \\
$>6.5$ mg/dL & \\
LEUCOCYTES COUNT, / $\boldsymbol{\mu L}$ & $163(71.2)$ \\
$>10.000$ & $66(28.8)$ \\
<10.000 & \\
OSTEOMYELITIS & $77(26.6)$ \\
Yes & $111(73.4)$ \\
No & \\
MANAGEMENT & $101(44.1)$ \\
Conservative & $74(32.3)$ \\
Debridement & $54(23.6)$ \\
Amputation &
\end{tabular}

Besides of characteristic of the patients, the diabetic foot ulcer was also precipitated with the condition of underlying disease of the patients. Figure 1 described the comorbid disease of the present study population with most of cases (62.0\%) had hypertension as underlying disease. All stages chronic kidney disease and heart failure were counted in $12.7 \%$ and $10 \%$ in present population, respectively. The amputation type was varies from major amputations (below the knee and above the knee amputation) and minor amputations (transmetatarsal, metatarsophalangeal disarticulation, toe disarticulation, and ankle disarticulation). In major amputation, below the knee was $25.9 \%$ patients and for minor amputation, predominantly was metatarsophalangeal disarticulation, see Table 2. Major amputation rate for this population was $9.6 \%$ and minor amputation rate was $14 \%$, with overall amputation rate was $23.6 \%$, Table 2.

Sepsis and death were an outcome that we chose to describe morbidity and mortality rate. Of $6.5 \%$ patients underwent a sepsis condition with overall mortality rate was $3.9 \%$, see Table 3 . Despite the morbidity and mortality rate, Table 4 showed that female patients had higher percentage in controlling HbA1C level $(<6.5 \mathrm{mg} / \mathrm{dL})$ than male patients $(21 \%$ vs. $10.5 \%$, respectively). A higher Wagner classification represented a poorer $\mathrm{HbA} 1 \mathrm{C}$ level and more in operative treatments, see Table 4.

Table 2. Type of Amputation

\begin{tabular}{lc}
\hline Variable & Cases $(\mathbf{n = 5 4 ) , ~ n ~ ( \% ) ~}$ \\
\hline Below knee & $14(25.9)$ \\
Above knee & $8(14.8)$ \\
Transmetatarsal & $2(3.7)$ \\
Metatarsophalangeal & $23(42.6)$ \\
disarticulation & \\
Toe disarticulation & $6(11.1)$ \\
Ankle disarticulation & $1(1.9)$ \\
\hline
\end{tabular}

\begin{tabular}{lc} 
& Table 3. Outcome \\
\hline \multicolumn{2}{c}{ Cases, $(\mathbf{n = 2 2 6}), \mathbf{n ~ ( \% )}$} \\
\hline Sepsis & $15(6.5 \%)$ \\
Death & $9(3.9 \%)$ \\
\hline
\end{tabular}

\section{DISCUSSION}

\section{Age}

From this study a varied age was obtained, the youngest were 20 years and the oldest were 88 years with median age 56 years and the most age is

\section{Comorbid Disease}

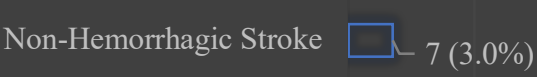

Chronic Kidney Disease

Pneumonia
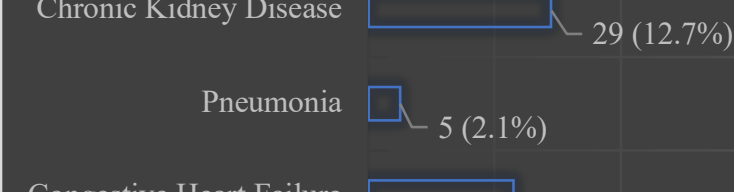

Congestive Heart Failure

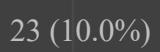

Hypertension

Figure 1. Comorbid Disease 
in the $6^{\text {th }}$ decade with $41 \%$. Research by Jawed $M$. Akter, et al in 2013 at the Indian Education Hospital obtained a number of $47 \%$ ( 26 persons) aged $41-60$ years old, $40 \%$ (22 persons) aged $60-80$ years old, and $12.7 \%$ ( 7 persons) aged $20-40$ years old. ${ }^{6}$ The population in Indonesia for diabetic foot still predominantly in fifth and sixth decade. In Table 1 showed more than $78 \%$ patients had age more than 50 years, but unfortunately the diabetic foot also existed in a younger patients ( $<30$ years). A decent healthy lifestyle should be more improved in Indonesian population to prevent diabetic complications further.

\section{Gender}

From 229 patients in this study, there were $116(50.05 \%)$ and $113(49.95 \%)$, male and female patients, respectively. A global epidemiologic study of diabetic foot conducted by Pengzi Zhang e.t al. showed that diabetic foot patients are more common in males than women, this can be associated with more intense physical activity of males. ${ }^{7}$ Also, a study in the United States amounted $15-20 \%$, where the comparison was, in men 6.5/1000, while in women $6.1 / 1000 .^{2}$ However, this is inversely proportional to the research conducted by Chodijah, et al, out of 27 patients, there are $23(85 \%)$ female and $4(15 \%)$ male. ${ }^{8}$ From this perspective, Indonesian population toward gender had no significant difference, even there was slightly higher in men then women. Diabetic foot as diabetic complications could happened in both gender, equally. This makes a more reasonable value to take a more attention in healthy lifestyle in both gender, male and female.

\section{Wagner's Classification}

Indonesian, a neuropathy and ischemic type (mixed type) is more prominent, and it explains the condition why people had more negligence in their podiatry treatment due to neuropathy condition. Indonesian people tends to hold their disease until a very severe condition then they come to hospital facility. If we see further in Table 2, an overall amputation rate ( $>25 \%)$ was existed in this study population.

\section{HbA1C Level}

In this study we found 157 patients $(68.2 \%)$ with level of $\mathrm{HbA1C}>6.5 \mathrm{mg} / \mathrm{dL}$, with an average of $9.98 \mathrm{mg} / \mathrm{dL}$. This is indicates poor DM control criteria. High blood glucose levels will decrease the ability of red blood cells to bind the oxygen, resulting in subsequent tissue hypoxia which further proliferate on the subendotel muscle cell wall. ${ }^{10}$ High levels of $\mathrm{HbA} 1 \mathrm{C}$ can also be assessed with Wagner degree from sufferers (Table 4), where obtained about 61 patients with Wagner 4 and 45 patients with Wagner 5 which lead to debridement and amputation. While patients with controlled HbA1C mostly on Wagner 2 with a total of 42 people and 4 people on Wagner 1 that can be dealt with conservatives.

In another study $\mathrm{HbA} 1 \mathrm{C}$ level average was $8.83 \mathrm{mg} / \mathrm{dl}$ in patients with diabetes mellitus type 2 , and it shows the poor control of the patient's blood sugar. ${ }^{11}$ At the Indian research the average of $\mathrm{HbA} 1 \mathrm{C}$ level was $8.9 \pm 1.88$ and $8.8 \pm 1.76$ in male and female patients, respectively. ${ }^{11-12}$

In Divakar Choubey et al. research, they found a total of $80 \%$ of patient with uncontrolled $\mathrm{HbA1C}$. The severe degree of wound usually has a poor blood glucose control that requires longer treatment and at grade 4 and grade 5 amputation was performed. Well-controlled blood glucose and proper

Table 4. Distribution According to Gender, Wagner Classification, HbA1C, and Type of Treatments

\begin{tabular}{|c|c|c|c|c|c|}
\hline & \multicolumn{2}{|c|}{$\begin{array}{l}\text { HbA1C Level } \\
(n=229) \text {, n (\%) }\end{array}$} & \multicolumn{3}{|c|}{$\begin{array}{l}\text { Treatments } \\
(n=229), n(\%)\end{array}$} \\
\hline & $<6.5 \mathrm{mg} / \mathrm{dL}$ & $>6.5 \mathrm{mg} / \mathrm{dL}$ & Conservative & Debridement & Amputation \\
\hline Male & $24(10.5)$ & $92(40.2)$ & $44(19.2)$ & $44(19.2)$ & $28(12.2)$ \\
\hline Female & $48(21.0)$ & $65(28.4)$ & $58(25.3)$ & $30(13.1)$ & $26(11.4)$ \\
\hline \multicolumn{6}{|c|}{ Classification } \\
\hline Wagner I & $4(1.7)$ & - & $4(1.7)$ & - & - \\
\hline Wagner II & $42(18.3)$ & $12(5.2)$ & $54(23.6)$ & - & - \\
\hline Wagner III & $19(8.3)$ & $39(17.0)$ & $38(16.6)$ & $20(8.7)$ & - \\
\hline Wagner IV & $7(3.1)$ & $61(26.6)$ & $5(2.2)$ & $52(22.7)$ & $11(4.8)$ \\
\hline Wagner $\mathrm{V}$ & - & $45(19.7)$ & - & $2(0.9)$ & $43(18.8)$ \\
\hline
\end{tabular}

In this study, we found 4 patients $(1.7 \%), 54$ people $(23.6 \%), 58$ people $(25.3 \%), 68$ people $(29.7 \%)$ and 45 people $(19.7 \%)$ with Wagner grade 1 , grade 2, grade 3, grade 4, and grade 5, respectively. Another study conducted by Misbah Mehr, found there are $30.6 \%, 26.5 \%$, and $42.9 \%$ patients with Wagner grade I, grade 2, and grade 3, respectively (9). A research conducted by Jawed $M$. Akhter et. Al. has 9 patients $(16.5 \%)$ with Wagner grade 1,19 patients $(34.5 \%)$ with Wagner grade 2 , 13 patients $(23.6 \%)$ with Wagner grade 3,11 patients $(20 \%)$ with Wagner grade 4,3 patients $(5.4 \%)$ with Wagner grade $5 .{ }^{6}$ Wagner classification is the most easiest classification in diabetic foot ulcer classification, and it helps clinician to evaluate the treatment results. In this study, see Table 1 , higher Wagner classification had more predominant, it proofed that in Indonesian population had more negligence in wound management. Almost $75 \%$ patients underwent in Wagner 3, 4, and 5 . In intervention on new wounds could prevent progression to heavier wounds.

\section{Leukocytes Level}

In this study we found 163 patients $(71.2 \%)$ with leucocytosis $(>10,000 / \mu \mathrm{L})$ and 66 patients $(28.8 \%)$ with normal leukocytes level $(<10,000 / \mu \mathrm{L})$. While another study conducted in Nigeria by Edo, et. al. was found 22 patients $(36 \%)$ with leukocytes $>10,000 \cdot{ }^{13}$ Diabetes mellitus patients have impaired in inflammatory response to infection, netrophil disorder, chemotaksis, phagocytosis, also decreased $\mathrm{T}$-cell response found in patients with diabetes compared to non. ${ }^{2}$

\section{Management}

In this study we carried out 3 therapeutic approaches where conservative therapy was conducted in 101 patients $(44.1 \%)$, debridement measures conducted in 74 patients $(32.3 \%)$, and 
amputation conducted in 54 patients $(23.6 \%)$. The amputation carried out includes major and minor amputations. Major amputation includes amputation above the knee and below the knee. Amputation done on Wagner 4 and 5 . Factors that affecting the amputation level are the size and location of ulcers, outpatient status, and the blood's supply in the legs. ${ }^{14}$ Major amputation including below knee and above knee amputation performed on 22 cases and minor amputation (ankle, transmetatarsal, metacarpophalangeal, toe disarticulation) performed on 32 cases (Table 2). In the Zubair study, M. Malik, India, from 162 cases amputated as many as 46 cases $(28.3 \%)$, and conservative as many as 116 cases $(71.7 \%){ }^{12}$

\section{Osteomyelitis}

This study found 77 patients (26.6\%) with radiological examination result of pedis osteomyelitis. Osteomyelitis is the most significant factor. Infection begins with trauma on the lower limbs which is the and resulting an ulcers, accompanied by an invasion and the growing of germs in ulcers, where usually are derived from the skin around the ulcer. ${ }^{15}$ In patients with DM, uncontrolled blood glucose levels cause leukocyte abnormalities, thus the function of the chemotaxis in the location of inflammation is interrupted, also the phagocytosis and bactericide are decreases, resulting difficulties to destroy the microorganisms by intra-cellular phagocyticbacteriosis system. Osteomyelitis is usually due to non-healing ulcers and it is associated with high risk of major amputation. Osteomyelitis is a common diabetic foot ulcers infection, being present in 10\%$15 \%$ of moderate and in $50 \%$ of severe infections. ${ }^{15}$

\section{Comorbid Factors and Outcomes}

Comorbid factors are able to aggravate the outcome of the diabetic foot, and in this study we found hypertension as the most comorbid factor suffered by patients with 142 patients, then followed by chronic kidney disease, congestive heart disease, non hemorrhagic stroke and pneumonia in 29, 23, 7, and 5 patients, respectively.

Smithamol Sunny et. al. in 2019 found that out of 96 patients, there were 22 patients with single comorbid and 74 patients with multiple comorbid including, hypertension 52 patients, dyslipidemia 41 patients, heart disease 12 patients and kidney disease 9 patients. ${ }^{16}$

From 229 to our patients, there are 16 patients $(6.9 \%)$ who devoleped sepsis (Table 3$)$. In our study, 9 patients were death due to septic shock leukocytosis $>10000 / \mu \mathrm{L}$.) accompanied by several related diseases.

\section{CONCLUSION}

The result of this research illustrates the profile of diabetic foot sufferers hospitalized in Wahidin Sudirohusodo Hospital. Diabetic foot ulcers often occur, and often causing amputation and death. The main treatment is to control the blood sugar level (HbA1C), the source control of infections through debridement, and amputation. Proper handling of new wounds should prevent the wound from progressed to worse.

\section{CONFLICT OF INTEREST}

The author states the original work, and there is no conflict of interest in doing this research.

\section{ORCID ID OF AUTHORS}

Julcrithno Irawan

https://orcid.org/0000-0002-3888-8020

Mulawardi Mulawardi

https://orcid.org/0000-0002-9482-0012

\section{REFERENCES}

1. Frykberg RG, Banks J. Management of Diabetic Foot Ulcers: A Review. Fed Pract. 2016 Feb;33(2):1623.

2. Del Core MA, Ahn J, Lewis RB, Raspovic KM, Lalli TAJ, Wukich DK. The Evaluation and Treatment of Diabetic Foot Ulcers and Diabetic Foot Infections. Foot Ankle Orthop. 2018 Jul $3 ; 3(3): 247301141878886$.

3. Jeffcoate WJ, Vileikyte L, Boyko EJ, Armstrong DG, Boulton AJM. Current Challenges and Opportunities in the Prevention and Management of Diabetic Foot Ulcers. Diabetes Care. 2018 Apr 20;41(4):645-52.

4. Mihardja L, Soetrisno U, Soegondo S. Prevalence and clinical profile of diabetes mellitus in productive aged urban Indonesians. J Diabetes Investig. 2014 Sep;5(5):507-12.

5. Soewondo P, Ferrario A, Tahapary DL. Challenges in diabetes management in Indonesia: a literature review. Global Health. 2013 Dec 3;9:63.

6. Jawed Mohammad Akther, Imran Ali Khan, Shahpurkar V V, Khanam N, Zahiruddin Quazi Syed. Evaluation of the diabetic foot according to Wagner's classification in a rural teaching hospital. Br J Diabetes Vasc Dis. 2011 Mar 23;11(2):74-9.

7. Zhang P, Lu J, Jing Y, Tang S, Zhu D, Bi Y. Global epidemiology of diabetic foot ulceration: a systematic review and meta-analysis. Ann Med. 2017 Feb 17;49(2):106-16.

8. Chodijah S, Nugroho A, Pandelaki K. HUBUNGAN KADAR GULA DARAH PUASA DENGAN JUMLAH LEUKOSIT PADA PASIEN DIABETES MELLITUS DENGAN SEPSIS. J e-Biomedik. 2013 Mar 13;1(1).

9. Mehraj DM. A review of Wagner classification and current concepts in management of diabetic foot. Int J Orthop Sci. 2018 Jan 1;4(1n):933-5.

10. Eliana F, Suwondo P, Hakim Makmun L, Saksono Harbuwono D. Faktor risiko disfungsi endotel pada prediabetes. Yars Med Journal; Vol 17, No 3 Sept - DESEMBER 2009DO - 1033476/jky.v17i3211. 2009 Oct 10 ;

11. Ghari Arab A, Zahedi M, Kazemi Nejad V, Sanagoo A, Azimi M. Correlation between Hemoglobin A1c and Serum Lipid Profile in Type 2 Diabetic Patients Referred to the Diabetes Clinic in Gorgan, Iran. J 
Clin Basic Res. 2018;2(1).

12. Zubair M. Glycosylated Hemoglobin in Diabetic Foot and its Correlation with Clinical Variables in a North Indian Tertiary Care Hospital. J Diabetes Metab. 2015;06(07).

13. Edo A, Edo G, Ezeani I. Risk factors, ulcer grade and management outcome of diabetic foot ulcers in a Tropical Tertiary Care Hospital. Niger Med J. 2013;54(1):59.

14. Venermo M, Manderbacka K, Ikonen T, Keskimäki I, Winell K, Sund R. Amputations and socioeconomic position among persons with diabetes mellitus, a population-based register study. BMJ Open. 2013 Apr 8;3(4):e002395.

15. Beard JD. Chronic lower limb ischemia. West J Med. 2000 Jul 1;173(1):60-3.

16. PRADEEP S, NN SUNNY AA, PARTHASARATHY R, RAJESHKUMAR S, SUNNY S. Patient counseling, risk factors and comorbidity assessment in diabetic foot ulcer. J Res Pharm. 2019 Feb 23;23(2):298-303. 